\title{
Pobreza e desigualdades sociais: tensões entre direitos, austeridade e suas implicações na atenção primária
}

\author{
Poverty and social inequality: tensions between rights and austerity \\ and its implications for primary healthcare
}

Delane Felinto Pitombeira (https://orcid.org/0000-0002-2237-3313) ${ }^{1}$

Lucia Conde de Oliveira (https://orcid.org/0000-0001-8265-7476) ${ }^{1}$

${ }^{1}$ Programa de Pós-

Graduação em Saúde Coletiva, Universidade Estadual do Ceará. Av. Dr. Silas Munguba 1700, Campus do Itaperi. 60714 903 Fortaleza CE Brasil. delane.pitombeira@uece.br

\begin{abstract}
The relationship between poverty and healthcare is evident in Brazilian society, constituting one of the faces of the inequalities resulting from a perverse social context. Focusing specifically on primary healthcare, this review of the literature on health policy highlights the tensions between the social question, social rights, and current austerity policies, and the latter's effects on healthcare for the poorest segments of the population. The 1988 Constitution represents a social pact that goes against the principles of austerity policies imposed by neoliberalism. With the deepening financial crisis and approval of Constitutional Amendment 95/2016, social protection policies such as those underpinning Brazil's national health system ("Sistema Único de Saúde") find themselves under threat, with direct consequences for the country's population. Despite the country's achievements in improving access to healthcare for the poorest, austerity measures are likely to strengthen barriers, seriously threatening the progress made in operationalizing the right to health. Therefore, considering that primary healthcare is a differentiated care model, this study reiterates the relationship between primary care and the social dimension, given that the impacts of the dismantling of social policies on population health are already being felt.
\end{abstract}

Key words Poverty, Austerity, Health inequalities, Primary Healthcare, Family Healthcare Strategy
Resumo As relações entre pobreza e saúde são percebidas no cotidiano da sociedade brasileira, constituindo faces das desigualdades de um contexto social perverso. Este artigo é uma revisão da literatura sobre a política de saúde, especificamente no âmbito da atenção primária, evidenciando as tensões entre a questão social, os direitos sociais, as atuais políticas de austeridade e suas implicações nos cuidados em saúde da população mais pobre. A partir da Constituição de 1988, celebrase um pacto social, que entra em contradição com as políticas de austeridade impostas pelo neoliberalismo. Com o agravamento da crise do capital e a Emenda Constitucional 95/2016, as políticas de proteção social pautadas na seguridade social, como o Sistema Único de Saúde, encontram-se ameaçadas, com consequências diretas para a população. Mesmo reconhecendo as conquistas no acesso à saúde da população mais pobre, as barreiras que atravessam essa realidade podem ser agravadas, pondo em risco os direitos conquistados. Portanto, ao considerar a Atenção Primária à Saúde como modelo de cuidado diferenciado, reitera-se sua relação com a dimensão social, uma vez que já se fazem sentir os impactos do desmonte das políticas sociais na saúde da população.

Palavras-chave Pobreza, Austeridade, Desigualdades em saúde, Atenção Primária à Saúde, Estratégia Saúde da Família 


\section{Introdução}

As relações entre pobreza e saúde podem ser percebidas no cotidiano da vida da sociedade brasileira e evidenciadas nos serviços de saúde. Por estarem historicamente e estruturalmente forjadas na sociedade, a pobreza e as desigualdades constituem faces de um contexto social perverso, estando implicadas no campo da saúde.

Partindo dessa realidade, o social impõe-se tanto no âmbito epistemológico, quanto nas práticas cotidianas, na perspectiva da produção do cuidado. Ao defender a saúde como produção social, a Saúde Coletiva tem destacado a determinação social como base para a compreensão dos processos saúde-doença. Nessa esteira, a compreensão de que a democracia é o berço para uma saúde universal, integral e equânime dimensiona um posicionamento político em busca de um processo de "articulação ali realizada entre o social e as dimensões técnico-científicas da saúde" ${ }^{\prime}$, gerando tensões, inclusive, com as concepções hegemônicas da área. Alinhada a essa reflexão, Cohn" afirma haver "nos anos recentes um processo de despolitização da saúde no País, seja enquanto produção de conhecimento seja enquanto processo de implantação do SUS", acrescentando existir uma maior preocupação com a tecnificação na forma de efetivação das políticas e programas de saúde.

Faz-se importante reconhecer, no entanto, que diante de um contexto social que se funda na trama da acumulação do capital e da concentração de riquezas, as pautas da cidadania e das políticas sociais apresentam-se cada vez mais desafiadoras. A implementação de políticas sociais, mesmo assentadas no campo constitucional, a exemplo da seguridade social, constitui campo de tensão permanente entre Estado e sociedade, perpassado por interesses diversos.

Tratar do avanço das desigualdades no contexto brasileiro é falar sobre o recrudescimento da pobreza no país, tornando mais evidentes as diferenças de renda, gênero, raça/etnia, bem como as diferenças regionais. O Brasil é considerado como um dos países que mais concentra renda no topo da pirâmide social. Num país com mais de 200 milhões de pessoas, os 10\% mais ricos estão entre aqueles que ganham mais de dez salários mínimos. Dentre estes, $75 \%$ ganham até 20 salários mínimos, sendo que $1 \%$, ou seja, 1,2 milhão de pessoas respondem por rendimento médio superior a R\$55.000 por mês ${ }^{3}$. Ao se tomar o percentual de pessoas vivendo com até 1/2 salário mínimo, identifica-se esse rendimen- to presente na metade da população do Norte e do Nordeste, enquanto que nas demais regiões esse percentual varia entre $15,6 \%$ e $21,5 \%$. Se a referência for de um salário mínimo per capita, o Nordeste possui $77,3 \%$ de pessoas residentes em domicílios particulares nessa situação, e a região Norte possui $76 \%$. A região Sudeste possui 50,2\%; a região Centro-Oeste, $52 \%$; e a região Sul, $42,3 \%{ }^{4}$. Quanto ao mercado de trabalho, ainda segundo o IBGE, o primeiro trimestre de 2019 foi bem difícil para os brasileiros. A taxa nacional de desocupação foi de $12,7 \%$ no período, identificando que as 14 taxas acima do indicador nacional estão distribuídas entre o Norte e o Nordeste, além do Rio de Janeiro, São Paulo e Distrito Federal.

As estatísticas apontam a gravidade da questão social brasileira, que, por um lado, tem aprofundado a condição de empobrecimento da maioria da população e, por outro, acirrado as desigualdades sociais resultantes da concentração de riquezas por uma parcela mínima dos mais ricos. As desigualdades regionais ficam evidentes, uma vez que as regiões Norte e Nordeste figuram em, praticamente, todos os indicadores, em grande desvantagem frente às demais do país.

Retomando especificamente as discussões sobre as relações entre pobreza, desigualdades e saúde, os questionamentos de Schraiber ${ }^{1}$ e Cohn ${ }^{2}$, oportunamente diante do cenário atual brasileiro, soam como uma convocação, no sentido de se buscar refazer as tramas da produção social dos processos saúde-doença-cuidado, diante do momento de retrocessos e de austeridade em que se encontra a sociedade.

Tomando como referência uma perspectiva ampliada de saúde, o SUS enfatiza as repercussões do contexto social e histórico na saúde da população. Ao determinar a saúde como "direito de todos e dever do Estado", a Constituição de 1988 explicita a conquista da saúde por meio dos fatores determinantes e condicionantes, como mediante a necessidade de garantir "às pessoas e à coletividade condições de bem-estar físico, mental e social"'. Nesse contexto, a Atenção Primária à Saúde (APS) constitui concepção basilar das práticas da área, ganhando complexidade frente à determinação social dos processos saúde-doença.

Assim, considera-se que a pobreza se impõe como realidade e como desafio aos processos de cuidado, seja para os usuários que convivem cotidianamente nessa situação e que trazem em seus corpos e subjetividades as marcas de uma vida atravessada pelo "sofrimento social"; seja para os 
profissionais que são afetados por ela, mediante as difíceis condições de trabalho, ou mesmo por se sentirem impotentes frente à grandeza que a dimensão social impõe $e^{6}$.

Diante de tal realidade, como os retrocessos dos direitos sociais repercutem nos cuidados em saúde da população mais pobre, especialmente no contexto da atenção primária? Partindo dessa questão, o artigo se propõe a fazer uma revisão da literatura sobre a política de saúde, especificamente no âmbito da atenção primária, evidenciando as tensões entre a questão social, os direitos sociais, as atuais políticas de austeridade e suas implicações nos cuidados em saúde da população mais pobre.

\section{Direito à saúde e austeridade: tensões da questão social brasileira}

A questão social funda-se no final do século XVIII, no período da Revolução Industrial, em que uma nova caracterização da pobreza se instaurava com o capitalismo. A pauperização massiva da classe trabalhadora e o aprofundamento da pobreza, ao mesmo tempo em que se dava a acumulação da riqueza, são características fundantes da questão social, estando sustentadas na exploração presente na relação capital/trabalho.

Nesse sentido, Paulo Netto ${ }^{7}$ afirma com ênfase que "a questão social é constitutiva do capitalismo", afastando-se da ideia de ser consequência transitória, ou mesmo resultante de fraquezas morais ${ }^{8}$. A pobreza passava, então, a ser consequência da exploração ilimitada do capital sobre o trabalho, em um momento em que havia um grande crescimento econômico. É nesse contexto que novas medidas de políticas sociais são acionadas, pressionadas pelos movimentos de trabalhadores que se organizavam à época. Num momento em que a ajuda voluntária e a caridade já não davam conta de apaziguar a pobreza, entram em cena ações oriundas do Poder Público, especialmente de proteção à saúde dos trabalhadores e ao desemprego.

Considera-se esse movimento como o embrião dos direitos sociais, constituídos no século XX. A cidadania torna-se referência, principalmente no Pós-Segunda Guerra Mundial, período denominado como "três décadas gloriosas", em virtude do crescimento econômico e da implementação do Welfare State nos países da Europa Nórdica e em parte da Europa Ocidental, além do dinamismo da economia americana. Segundo Paulo $\mathrm{Netto}^{7}$, essa nova dinâmica do capitalismo “parecia remeter para o passado a questão social e suas manifestações - elas seriam um quase privilégio da periferia capitalista, às voltas com seus problemas de "subdesenvolvimento"”.

A partir da década de 1970, forma-se uma nova crise do capitalismo, caracterizada pela acumulação desenfreada do capital, mais especificamente do capital financeiro, responsabilizando o Estado e o gasto público pela crise, e indicando como solução a redução do tamanho do Estado e o corte dos gastos. Para Fiori ${ }^{9}$, toda a ofensiva neoliberal foi direcionada à desconstrução do Welfare State, resultando numa "vitória ideológica que abre portas e legitima uma espécie de selvagem vingança do capital contra a política e contra os trabalhadores”. Na mesma direção, Iamamoto $^{10}$ ressalta o papel do Estado na financeirização da economia, por um lado mediante a privatização do Estado, o desmonte das políticas sociais, a mercantilização dos serviços e a flexibilização da legislação trabalhista e, por outro, com a redução dos custos empresariais (redução do "fator trabalho" e aumento da exploração). Diante disso, o Estado mínimo implica o Estado máximo para o capital, impondo uma lógica paradoxal: ao passo que resulta num crescimento econômico exponencial, aprofunda as desigualdades de toda ordem.

Mesmo afirmando que a flexibilização (da produção, das relações de trabalho), a desregulamentação (das relações comerciais e dos circuitos financeiros) e a privatização constituem as três frentes desse novo projeto restaurador, Paulo $\mathrm{Netto}^{7}$ ressalva que "é evidente que o tardo-capitalismo não liquidou com o Estado Nacional, mas é também claro que vem operando no sentido de erodir a sua soberania - todavia, cumpre assinalar a diferencialidade desta erosão, que atinge diversamente Estados centrais e Estados periféricos (ou mais débeis)".

Nessa perspectiva, o Brasil, caracterizado como país de capitalismo dependente e marcado por um passado colonial, insere-se de forma diferenciada nessa realidade, enfrentando também de forma peculiar a questão social. Ao situar o Brasil "nas revoluções burguesas tardias", Guerra et al. ${ }^{11}$ afirmam que aqui "a mudança social esteve sob o controle quase monopolizado de interesses antissociais e autoritários", com políticas sociais restritas a segmentos específicos da população, como estratégias de legitimação do poder dominante. Desse modo, o crescimento da economia se deu apartado da integração social, fazendo com que o Brasil, em 1980, período em que o país figurava entre as maiores economias 
do mundo, estivesse também entre os três países de maior desigualdade de renda ${ }^{11}$.

Foi no contexto da Constituição de 1988, contudo, que se tornou possível experimentar a construção de uma nova proposta de proteção social no país, tendo o modelo da seguridade social como seu marco fundante. Os direitos sociais passaram a tomar como referência a concepção de universalização da cidadania, com as políticas sociais organizadas a partir das necessidades da população, no âmbito da justiça social. Para Teixeira e Pinho ${ }^{12}$, "a inclusão da previdência, da saúde e da assistência, como partes da Seguridade Social, introduz a noção de direitos sociais universais como parte da condição de cidadania, antes restritos à população beneficiária da previdência". Assim, esse novo modelo se caracteriza pela "universalidade da cobertura, pelo reconhecimento dos direitos sociais, pela garantia e dever do Estado e pela subordinação do setor privado".

Na primeira década do século XXI, no Brasil, a despeito das contradições do mundo globalizado e da crise do Welfare State, pode-se perceber o crescimento econômico associado à redução da pobreza. O aumento da renda oriunda da elevação dos postos de trabalho e decorrente da expansão econômica, associado aos investimentos nas políticas sociais e às políticas de acesso e garantia de renda à população situada na extrema pobreza, constituíram elementos importantes no reconhecimento das mudanças pelas quais passaram a sociedade brasileira ${ }^{11}$.

No entanto, desde 2016, o Brasil tem vivido um profundo retrocesso, com a ameaça aos ganhos sociais conquistados, a exemplo dos ataques sucessivos às políticas sociais, fragilizando ainda mais as condições de vida e de saúde da população, além de evidenciar a presença de diferentes interesses na sociedade. Como afirma Paim ${ }^{13}$, mesmo considerando o aumento de rendimentos por todos os segmentos sociais, "as forças do capital empreenderam um golpe parlamentar em 2016 para impor à maioria da população trabalhadora o onus das políticas de ajuste, com um novo regime fiscal e reformas previdenciária e trabalhista".

Desde então, tem-se presenciado no país um projeto político em oposição às conquistas democráticas. Como aponta Pochmann ${ }^{14}$, os avanços sociais e a diminuição de desigualdades registradas desde os anos 2000 não constituíam projeto de toda a sociedade. Pelo contrário, gerou muitas insatisfações em setores da classe média e da classe dominante, agravadas pelo aprofundamento da crise do sistema financeiro em 2008. Dessa for- ma, o golpe de 2016 abre espaço para a retomada do projeto iniciado nos anos 1990, parcialmente interrompido com os governos do Partido dos Trabalhadores, recolocando o Brasil na geopolítica mundial alinhado aos interesses norte-americanos, sendo apontadas as reformas trabalhista, fiscal e da previdência, tal como a Emenda Constitucional (EC) 95/2016, como saída para a retomada do crescimento econômico, a volta do emprego e a promoção do bem-estar social.

A EC 95/2016 institui o "Novo Regime Fiscal", congelando os gastos públicos nos próximos vinte anos, retomando os princípios da "austeridade" como orientadores da gestão pública. Entretanto, esse congelamento não incidiu sobre os gastos da dívida pública, que no orçamento federal executado em 2018 representou $40,66 \%{ }^{15}$. Pouco se sabe sobre os gastos com os serviços da dívida pública, seus credores, não sendo nem mesmo questionados os termos dos contratos. Pautados nos interesses do sistema financeiro, a formação do superavit primário é a meta de vários governos, garantindo o que seria, na linguagem do Banco Central, a capacidade do governo de honrar seus compromissos com a dívida pública. Com suporte nas reflexões de Eric Toussaint, descritas por Bovy ${ }^{16}$, pergunta-se: essa dívida é legítima, legal e sustentável ou odiosa?

Para Rossi et al. ${ }^{17}$, "uma decisão política que implica corte de gastos sociais pode ser também uma decisão sobre a privação do acesso a direitos". E indagam: "quais os efeitos da austeridade na ponta?". Teixeira e Pinho ${ }^{12}$ também questionam: "quais os impactos das reformas de austeridade sobre a rede de proteção social e o legado da Seguridade Social, consagrado quando da promulgação da Carta Magna de 1988?".

Esses questionamentos já apontam para a falta de legitimidade da dívida. Da forma como tem sido apresentada, a "austeridade" não aborda suas consequências para a inclusão social e as políticas sociais, especialmente para a proteção das pessoas mais pobres, que "dependem fortemente do Estado para incrementar suas rendas, bem como para acessar postos de saúde, hospitais, clínicas, postos de vacinação, creches e escolas de educação fundamental"3 , limitando ainda mais a capacidade do Estado de reduzir as desigualdades e de combater a pobreza. Nesse contexto, pode-se dizer que há uma "depreciação das políticas sociais"12, para que o mercado funcione com suas próprias leis, sem regulação ou proteção social. Assim, a indagação sobre os rumos do país remete às diretrizes sobre a garantia dos direitos à saúde. Como se garantirá a saúde da população 
diante de tal realidade, tendo em vista as desigualdades presentes no cotidiano da vida da população e dos serviços?

\section{Desigualdades, determinação social e seus reflexos no acesso à saúde}

As condições de saúde da população estão imbricadas à questão social, refletindo as condições de vida em que ela vive, e revelando em que medida o Estado apresenta-se (ou não) implicado no enfrentamento dessas questões $^{18}$. As desigualdades sociais constituem pontos de referência fundamentais para que se possa avançar na compreensão da vida humana, tanto no que diz respeito à doença, à morbidade, à mortalidade, quanto sobre a saúde, a qualidade e a extensão da vida ${ }^{19}$.

Nesse contexto, a determinação social dos processos saúde-doença ancora-se na ideia de que os "padrões estruturais de produção e reprodução de dominação, exploração e marginalização das sociedades concretas moldam os modos de vida e se expressam nos processos saúde-doença" ${ }^{20}$. Breilh ${ }^{21}$ aponta ainda sua perspectiva emancipadora, expondo que, mais do que a saúde, o que se está evidenciando é a "determinação social da vida" 22 , são as determinações sociais que implicam os modos de viver das pessoas e, por consequência, os processos saúde-doença.

Dessa maneira, é de grande importância compreender como as desigualdades presentes na organização social de cada sociedade são refletidas no estado de saúde da população, assim como no acesso dos serviços de saúde existentes, pois como afirma Barata ${ }^{23}$, "há sistemas que potencializam as desigualdades existentes na organização social e outros que procuram compensar, pelo menos em parte, os resultados danosos da organização social sobre os grupos socialmente mais vulneráveis".

Pode-se inferir, dessa forma, que a estruturação dos sistemas de saúde pode comportar tensões entre diferentes formas de se conceber os processos saúde-doença e, por conseguinte, de se planejar as ações no campo. Nesse cenário, além do sentido conceitual da determinação social no enfrentamento das desigualdades em saúde, Barreto ${ }^{24}$ lembra a coexistência desta com a concepção mais voltada ao campo das ciências biomédicas, cujas explicações sobre as doenças partem da compreensão essencialmente de suas causas biológicas, e pautadas por um "moderno" sistema que tenha como foco as tecnologias de prevenção, diagnóstico, cura e reabilitação.
As duas visões, por coexistirem no âmbito das explicações dos processos saúde-doença, disputam espaço não apenas no campo epistêmico, mas também no âmbito institucional e financeiro, o que resulta, comumente, em investimento de mais recursos na estruturação de sistemas de saúde, e menos nos determinantes sociais e ambientais que estariam na base de muitos problemas de saúde. Segundo Barreto ${ }^{24}$, mesmo com o avanço das tecnologias de saúde, não se tem observado a mesma correspondência na melhoria das condições de saúde das populações, principalmente quando estas são estratificadas por áreas geográficas, grupos sociais ou étnicos; afirmando ainda que, "não por acaso, os países pobres apresentam condições de saúde sempre piores quando comparadas aos que são ricos".

Por outro lado, expõe o autor, tem sido cada vez mais evidente que nos países com políticas que embasem um sistema de proteção social mais amplo, são observados impactos positivos nas condições de saúde da população, reiterando Travassos et al. ${ }^{25}$, ao afirmarem que sistemas mais equânimes possibilitam às pessoas, independentemente do grupo social, acessarem indistintamente os serviços de acordo com suas necessidades. Mas ainda são muitas as barreiras ${ }^{25}$ que se interpõem no acesso à saúde, as quais, na maioria das vezes, são impostas e vivenciadas pela população mais pobre.

Aproximando-se essa realidade da Atenção Primária à Saúde, em recente levantamento sobre a Estratégia Saúde da Família (ESF) realizado por Malta et al. ${ }^{26}$, os autores identificaram um aumento na cobertura, comparando a PNAD de 2008 e 2013 , passando de 50,9\% para 53,4\%. O crescimento da rede de atenção primária foi identificado pelos autores, chegando, em 2012, a uma cobertura de 95\% dos municípios brasileiros, contando com um total de 33.404 equipes de saúde da família implantadas, o que corresponde a $55 \%$ da população do país.

No entanto, desigualdades no acesso e no uso dos serviços foram percebidas, de acordo com as diferentes regiões do país. A zona rural tem quase a totalidade de sua população cadastrada na APS (aproximadamente $2 / 3$ da população - 70,9\%), se comparada com a área urbana (50,6 \%), com maior cobertura na região Nordeste, e menor na Sudeste. No Nordeste, a cobertura da ESF chega a $90 \%$, no Piauí e na Paraíba, e a $80 \%$, no Rio Grande do Norte, em Sergipe e no Maranhão, estando o Ceará com 73\% de cobertura ${ }^{26}$. Embora os autores considerem a importância da priorização da cobertura da ESF às populações mais vul- 
neráveis no enfrentamento das iniquidades sociais, fazem a ressalva de que apenas uma maior cobertura não responde à totalidade da saúde, necessitando, assim, de outras conquistas (processo de trabalho, insumos, fluxos, acessibilidade, equidade) para se obter mais qualidade sobre a produção do cuidado ${ }^{26}$.

Observa-se que a cobertura da ESF tem grande variação, a depender da densidade populacional do município. A efetividade da ESF é evidenciada nos municípios menores (até vinte mil habitantes, a cobertura refere-se a $90,73 \%$ ), ficando bastante aquém nos municípios maiores (40,93\% nos municípios com acima de 1 milhão de habitantes $)^{27}$. Giovanella e Mendonça ${ }^{28}$ ressaltam que nos municípios de pequeno porte a implantação da ESF ocorreu de forma rápida, enquanto nas grandes cidades complexos problemas dificultaram sua efetivação nos territórios, seja devido à estrutura social ou ainda em virtude da existência de uma rede assistencial já instalada, desarticulada, e com base no modelo assistencial tradicional.

A partir desses dados, pode-se perceber a persistência das desigualdades no tocante ao acesso à saúde, como também no que diz respeito à cobertura da ESF entre os diferentes segmentos da população brasileira. Tal como ressalta Barata ${ }^{23}$, "o enfrentamento das desigualdades sociais em saúde depende de políticas públicas capazes de modificar os determinantes sociais, melhorar a distribuição dos benefícios ou minorar os efeitos da distribuição desigual de poder e propriedade nas sociedades modernas".

Mas como pensar o enfrentamento das desigualdades em saúde diante das políticas de austeridade anunciadas na conjuntura atual? Como alertam Santos e Vieira ${ }^{29}$, no Brasil, os efeitos das políticas de austeridade tendem a ser mais graves do que em países considerados desenvolvidos, uma vez que, como já foi mencionado anteriormente, ele se encontra entre os países mais desiguais do mundo, e possui um sistema de proteção social ainda frágil.

Os efeitos tanto da crise econômica quanto das políticas de austeridade são mencionados por Paes-Sousa et al..$^{30}$, como impactando negativamente tanto na redução da pobreza quanto na saúde da população mais vulnerável, a exemplo dos índices de mortalidade infantil. Os autores afirmam que, "embora o País não tenha tido sucesso na redução da mortalidade por causas violentas, os avanços nas políticas públicas de saúde e de assistência social contribuíram decisivamente para a prevalência residual dos óbitos por des- nutrição e doenças diarreicas em crianças". Mencionam também a sequência de notícias, a partir de 2018, que sinalizam os retrocessos na saúde, a exemplo do risco de surto de sarampo e redução da sua cobertura vacinal, a ameaça da volta da poliomielite, enfatizando que "a redução de investimentos em saúde se faz sentir na atenção básica, afetando a oferta de serviços de promoção, prevenção e atenção" ${ }^{\prime 30}$.

Nesse momento, considera-se importante voltar à atenção básica, por se reconhecer a complexidade no cotidiano desse nível de atenção, tanto nos serviços como nas práticas profissionais, especialmente diante do contexto de grande vulnerabilidade. Considerando a dimensão social como constituinte da produção da saúde, que desafios são postos às práticas de cuidado na atenção primária?

\section{O social e o cuidado na Atenção Primária à Saúde: desafios [intensificados] em tempos de austeridade}

A Atenção Primária à Saúde (APS), também denominada Atenção Básica, vem historicamente acumulando importantes conquistas para a saúde da população e para a organização do SUS. A Política Nacional de Atenção Básica (PNAB), embora tenha apresentado ampliação entre primeira e segunda versões $\left(2006^{31}\right.$ e $\left.2011^{32}\right)$, tem, em sua revisão de $2017^{33}$, apresentado tensões no campo dos avanços conquistados e da consolidação do direito à saúde.

Mesmo preservando diretrizes, debates recentes sobre a nova $\mathrm{PNAB}^{34,35}$ destacam mudanças que apontam retrocessos na estruturação da atenção primária, e que podem ressoar na saúde da população, especialmente a mais pobre. Dentre estas, podem ser apontadas a fragilização da ESF, a qual deixa de ser prioridade como eixo orientador da APS; as mudanças na configuração do trabalho dos agentes comunitários, retirando a obrigatoriedade de sua presença na composição das equipes; e a precarização produzida pela reorientação do financiamento.

Sabe-se, porém, que com a estratégia de estruturação das Redes de Atenção à Saúde (RAS), a APS reafirmou seu papel de relevância dentro do sistema, constituindo porta de entrada prioritária, bem como configurando-se como o centro de comunicação das RAS e importante referência na coordenação do cuidado ${ }^{36}$. No entanto, a integração da APS na RAS constitui um desafio para o sistema ${ }^{34}$, aspecto abordado por Testa ${ }^{37}$. Ao contrapor a denominação atenção "primária" de 
atenção "primitiva”, o autor ${ }^{37}$ defende a primeira como sendo integrada ao sistema de saúde, servindo às necessidades da população, e não funcionando como um "serviço de segunda categoria”. Nessa esteira, a representação, comumente realizada da APS, como "medicina para pobres" ou "assistência simplificada e de baixo custo" 37 , diverge das diretrizes, que a situam como sendo o "primeiro nível de atenção e como estratégia de reorientação do sistema de saúde" ${ }^{38}$.

Assim, ao passo que é necessário afastar-se de qualquer menção que associe APS à medicina para pobres, faz-se relevante, a partir do princípio de equidade, reconhecer a questão social como constitutiva da sociedade brasileira, impondo condições diferenciadas (e injustas) de vida, de disponibilidade da rede de serviços, perpassando os processos de produção de cuidado ${ }^{39}$. Ao abordarem os processos de trabalho em saúde como encontros de sujeitos, corpos e afetos, Onocko Campos e Campos ${ }^{40}$ expõem que, em se tratando da realidade brasileira, e do trabalho dentro dos "bolsões de pobreza", o cuidado em saúde implica permanente intensidade e singularidade dessa experiência. Segundo os autores, “[...] o trabalho de defender a vida em algumas regiões é duro, doído, sofrido. [...] O contato permanente com a dor, o risco e o sofrimento ativam nossas próprias pulsões vitais" 40 .

Nessa perspectiva, o enfrentamento das expressões da questão social encontra-se engendrado na configuração do SUS, tanto como desafio na construção de um projeto político civilizatório, quanto no cotidiano dos serviços, os quais precisam ser reconhecidos como válidos dentro da relação existente entre a dimensão social e a esfera do cuidado. O território passa a ser fundamental nesse cenário, uma vez que as ações das equipes da ESF e NASF (Núcleo de Apoio à Saúde da Família) organizam-se mais próximas ao cotidiano da vida das pessoas. Para além da delimitação geográfica, o território caracteriza-se como "território de vida pulsante, de conflitos, de interesses diferenciados em jogo, de projetos e de sonhos. O território de uso na saúde é, simultaneamente, território solo e território econômico, político, cultural e epidemiológico" ${ }^{41}$. Da mesma forma que o território, a dimensão da subjetividade precisa ser reconhecida na composição da coprodução singular dos processos saúde-doençacuidado, evidenciando o sujeito (individual ou coletivo) como fator fundamental na construção da saúde sanitária ${ }^{42}$.

Nesse sentido, faz-se fundamental reconhecer que as equipes se sentem afetadas pela rea- lidade social, que, muitas vezes, mais paralisam do que possibilitam criar e inventar suas ações, precisando de "dispositivos desalienantes" 6 . Para os autores, os sofrimentos produzidos diante da realidade social vivenciada nas periferias das cidades refletem "subjetividades frágeis, precárias, violentadas e violentas", exigindo do campo da saúde estratégias em diferentes frentes: sanitária, clínica, social, produtiva. Por outro lado, diante do contexto de vulnerabilidade, os autores afirmam que, por mais empobrecido que seja determinado território, serão sempre as pessoas que lá vivem que poderão dizer das potencialidades locais, afastando-se da ideia de se transformar o cuidado em controle e vigilância da população ${ }^{6}$. Essas afirmações revelam como as tensões sociais presentes na sociedade implicam nos processos de cuidado no cotidiano dos serviços, levantando reflexões sobre quais são os caminhos a serem trilhados nos processos de cuidado na APS, diante de uma realidade de miséria e de desmonte das políticas sociais, não apenas da saúde, mas da própria seguridade social.

Diante desse contexto, desde o ano de 2016, especialmente com o aprofundamento da política de austeridade e das restrições impostas com a EC 95/2016, a Atenção Primária à Saúde encontra-se em risco de sofrer retrocessos, a exemplo dos desdobramentos que a nova PNAB (2017) $)^{33}$ sugere no cenário atual. Outra perda substancial para a APS, ainda no final de 2018, foi a mudança na condução do Programa Mais Médicos, especialmente com o cancelamento da parceria com o governo cubano, cujo convênio era estabelecido por intermédio da OPAS (Organização Pan-Americana de Saúde). A possibilidade de se conseguir o profissional médico para determinadas regiões do país, especialmente as mais longínquas e com alta vulnerabilidade social, foi um importante diferencial do programa na garantia de acesso à saúde para a população mais pobre $^{43}$, registrando-se, atualmente, dificuldades na garantia da assistência à saúde para essas populações.

Reafirmam-se, assim, as palavras de Sper$\operatorname{ling}^{44}$, de que "a atenção primária não é apenas o primeiro contato estruturado para atenção de pacientes, é, também, sem dúvida, campo em disputa para produção de significantes e significados no processo de cuidado da vida humana", o qual é afetado diretamente pelas desigualdades produzidas socialmente.

Diante do cenário preocupante para a saúde do país, parece fundamental o resgate do discurso "Democracia é Saúde", proferido por Sérgio 
Arouca na $8^{a}$ Conferência Nacional da Saúde, em 1986, como convocação política para o enfrentamento da conjuntura atual de desmonte do Sistema Único de Saúde ${ }^{45}$.

\section{Considerações finais}

A revisão de literatura aqui empreendida buscou analisar como a questão social, expressão das desigualdades forjadas na estrutura da sociedade brasileira, está imbricada com a dimensão do cuidado nas práticas em saúde. As implicações da pobreza e das desigualdades condicionam os cuidados em saúde e têm tomado proporções ainda maiores com as tensões entre os direitos e a austeridade em curso no país. Os embates permanentes entre diferentes projetos políticos, econômicos e ideológicos se acirraram desde o golpe de 2016, estando presentes também no âmbito do SUS, como têm afirmado os estudos recentes. Porém, é importante reconhecer que as disputas por diferentes projetos do SUS fazem parte da sua história.

A dimensão social atravessa e compõe a produção da saúde, não podendo ser vista de forma separada. Nesse sentido, assim como a afirmação "austeridade faz mal à saúde" tem sido expressa na Saúde Coletiva, aqui também se pede licença para reiterar que a concentração de renda, a não garantia de direitos constitucionais, o não respeito à diversidade fazem mal à saúde. São muitas as dúvidas e incertezas que têm se apresentado no horizonte do país e, mais especificamente, no horizonte da saúde da população mais pobre, que historicamente e cotidianamente sofre de forma mais intensa os impactos das desigualdades sociais. Em tempos de austeridade, cabe à sociedade, como convocou Arouca, encontrar caminhos de articulação e diálogo para a construção de outras perspectivas para o bem viver.

Cabe, no entanto, reafirmar que as políticas de austeridade propostas mediante o corte ou a contenção de gastos não se apresentam como solução para a crise, pois as experiências históricas em várias partes do mundo têm demonstrado seu agravamento. Precisa-se levar para a sociedade o debate sobre as suas necessidades e prioridades, a exemplo do direito ao cuidado integral à saúde, a fim de que se assegurem recursos que garantam as políticas sociais.

Finaliza-se, assim, essa revisão, reconhecendo a necessidade de maior aprofundamento das questões elencadas, e conjugando o verbo 'esperançar', acreditando na produção de novas (e outras) tessituras nas tramas de laços sociais mais solidários e equânimes para a sociedade.

\section{Colaboradores}

DF Pitombeira e LC Oliveira participaram integralmente da concepção e redação do artigo, da revisão crítica do conteúdo e da aprovação da versão final do manuscrito. 


\section{Referências}

1. Schraiber LB. Epistemologia em saúde coletiva na América Latina: questões do Brasil de uma perspectiva histórica. In: $12^{\circ}$ Congresso Brasileiro de Saúde Coletiva, Epistemologia em Saúde Coletiva na América Latina; 2018; Rio de Janeiro. p. 1-9.

2. Cohn A. Reformas da saúde e desenvolvimento: desafios para a articulação entre direito à saúde e cidadania. In: Cohn A, organizador. Saúde, cidadania e desenvolvimento. Rio de Janeiro: Centro Internacional Celso Furtado; 2013. p. 221-235.

3. Oxfam Brasil. País estagnado: um retrato das desigualdades brasileiras. São Paulo: Oxfam Brasil; 2018.

4. Instituto Brasileiro de Geografia e Estatística (IBGE). Coordenação de População e Indicadores Sociais. Rio de Janeiro: IBGE; 2018.

5. Brasil. Lei no 8.080/90, de 19 de setembro de 1990 . Dispõe sobre as condições para a promoção, proteção e recuperação da saúde, a organização e o funcionamento dos serviços correspondentes e dá outras providências. Diário Oficial da União 1990; 20 set.

6. Onocko Campos R, Massuda A, Valle I, Castaño G, Pellegrini O. Saúde coletiva e psicanálise: entrecruzando conceitos em busca de políticas públicas potentes. In: Onocko Campos R, organizador. Psicanálise e saúde coletiva: interfaces. São Paulo: Hucitec; 2012. p. 43-60.

7. Paulo Netto J. Uma face contemporânea da barbárie. Novos Rumos 2013; 50(1):26-35.

8. Pereira PAP. Política social: temas e questões. $3^{\mathrm{a}}$ ed. São Paulo: Cortez; 2011.

9. Fiori J. Neoliberalismo e Políticas Públicas. Rio de Janeiro: UERJ, IMS; 1996.

10. Iamamoto MV. "Questão social" no Brasil: relações sociais e desigualdades. ConCiencia Social 2018; 2(3):27-44.

11. Guerra A, Pochmann M, Silva RA, organizadores. Atlas da exclusão social no Brasil: dez anos depois. São Paulo: Cortez; 2014.

12. Teixeira SMF, Pinho CES. Liquefação da rede de proteção social no Brasil autoritário. R Katál 2018; 21(1):14-42.

13. Paim J. Prefácio. In: Rodrigues PHA, Santos IS, organizadores. Políticas e riscos sociais no Brasil e na Europa: convergências e divergências. $2^{a}$ ed. Rio de Janeiro: Cebes, São Paulo: Hucitec Editora; 2017. p. 7-8.

14. Pochmann M. A segunda globalização capitalista e o impasse nas políticas de bem-estar social. In: Rodrigues PHA, Santos IS, organizadores. Políticas e riscos sociais no Brasil e na Europa: convergências e divergências. $2^{\text {a }}$ ed. Rio de Janeiro: Cebes, São Paulo: Hucitec Editora; 2017. p. 163-177.

15. Auditoria Cidadã da Dívida (ACD). Orçamento Federal Executado em 2018 [página na Internet]. Brasília: ACD; 2019.

16. Bovy Y. Outros países vão seguir o exemplo da auditoria da dívida da Grécia? [página na Internet]. Carta Maior; 2015. [acessado 2019 Maio 25]. Disponível em: https://www.cartamaior.com.br/?/Editoria/Economia/Outros-paises-vao-seguir-o-exemplo-da-auditoria-da-divida-da-Grecia-/7/33140
17. Rossi P, Dweck E, Oliveira ALM. Introdução. In: Rossi P, Dweck E, Oliveira ALM, organizadores. Economia para poucos: impactos sociais da austeridade e alternativas para o Brasil. São Paulo: Autonomia Literária; 2018. p. 7-13.

18. Oliveira MJI, Santo EE. A relação entre os determinantes sociais da saúde e a questão social. Cad Saúde Desenvolv 2013; 2(2):7-24.

19. Almeida Filho N. A problemática teórica da determinaçao social da saúde (nota breve sobre desigualdades em saúde como objeto de conhecimento). Saúde Debate 2009; 33(83):349-370.

20. Borde E, Hernández-Álvarez M, Porto MFS. Uma análise crítica da abordagem dos Determinantes Sociais da Saúde a partir da medicina social e saúde coletiva latino-americana. Saúde Debate 2015; 39(106):841-854.

21. Breilh J. La determinación social de la salud como herramienta de transformación hacia una nueva salud pública (salud colectiva). Rev Fac Nac Salud Pública 2013; 31(1):13-27.

22. Breilh J. Una perspectiva emancipadora de la investigación e incidencia basada en la determinación social de la salud. Quito: UASB; 2011.

23. Barata RB. Como e por que as desigualdades sociais fazem mal à saúde. Rio de Janeiro: Editora Fiocruz; 2009.

24. Barreto ML. Desigualdades em Saúde: uma perspectiva global. Cien Saude Colet 2017; 22(7):2097-2108.

25. Travassos C, Oliveira EXG, Viacava F. Desigualdades geográficas e sociais no acesso aos serviços de saúde no Brasil: 1998 e 2003. Cien Saude Colet 2006; 11(4):975-986.

26. Malta DC, Santos MAS, Stopa SR, Vieira JEB, Melo EA, Reis AAC. A cobertura da Estratégia de Saúde da Família (ESF) no Brasil, segundo a Pesquisa Nacional de Saúde, 2013. Cien Saude Colet 2016; 21(2):327-338.

27. Instituto de Pesquisa Econômica Aplicada (IPEA). Políticas sociais: acompanhamento e análise. Brasília: IPEA; 2015.

28. Giovanella L, Mendonça MHM. Atenção Primária à Saúde. In: Giovanella L, Escorel S, Lobato LVC, Noronha JC, Carvalho AIC, organizadores. Políticas e Sistemas de Saúde no Brasil. Rio de Janeiro: Fiocruz; 2012. p. 493-545.

29. Santos IS, Vieira FS. Direito à saúde e austeridade fiscal: o caso brasileiro em perspectiva internacional. Cien Saude Colet 2018; 23(7):2303-2314.

30. Paes-Sousa R, Rasella D, Carepa-Sousa J. Política econômica e saúde pública: equilíbrio fiscal e bem-estar da população. Saúde debate 2018; 42(3):172-182.

31. Brasil. Portaria no 648/GM de 28 de março de 2006. Aprova a Política Nacional de Atenção Básica. Diário Oficial da União 2006; 24 out.

32. Brasil. Portaria $\mathrm{n}^{\circ} 2.488$, de 21 de outubro de 2011. Aprova a Política Nacional de Atenção Básica. Diário Oficial da União 2011; 27 dez.

33. Brasil. Portaria no 2.436, de 21 de setembro de 2017. Aprova a Política Nacional de Atenção Básica. Diário Oficial da União 2017; 17 nov. 
34. Cecílio LCO, Reis AAC. Apontamentos sobre os desafios (ainda) atuais da atenção básica à saúde. Cad Saude Publica 2018; 34(8):1-14.

35. Giovanella L. Atenção básica ou atenção primária à saúde? Cad Saude Publica 2018; 34(8):11-15.

36. Brasil. Portaria GM/MS no 4.279 , de 30 de dezembro de 2010. Estabelece diretrizes para a organização da Rede de Atenção à Saúde no âmbito do Sistema Único de Saúde. Diário Oficial da União 2010; 30 dez.

37. Testa M. Pensar em salud. Buenos Aires: Lugar Editorial; 2006.

38. Paim J. Desafios para a saúde coletiva no século XXI. Salvador: EDUFBA; 2006.

39. Mello GA, Fontanella BJB, Demarzo MMP. Atenção básica e atenção primária: origens e diferenças conceituais. Rev APS 2009; 12(2):204-213.

40. Onocko Campos R, Campos GWS. Co-construção de autonomia: o sujeito em questão. In: Campos GWS, Minayo MCS, Akerman M, Drumond Junior M, Carvalho YM, organizadores. Tratado de saúde coletiva. $2^{\text {a }}$ ed. São Paulo: Hucitec; 2012. p. 55-69.

41. Gondim GMM, Monken M. O uso do território na Atenção Primária à Saúde. In: Mendonça MHM, Matta GC, Giovanella L, organizadores. Atenção Primária à Saúde no Brasil: conceitos, práticas e pesquisa. Rio de Janeiro: Editora Fiocruz; 2018. p. 143-175.

42. Campos GWS. Clínica e saúde coletiva compartilhadas: teoria paidéia e reformulação ampliada do trabalho em saúde. In: Campos GWS, Minayo MCS, Akerman M, Drumond Junior M, Carvalho YM, organizadores. Tratado de saúde coletiva. São Paulo: $\mathrm{Hu}-$ citec; 2006. p. 41-80.

43. Reis V. Nota Abrasco sobre a saída dos médicos cubanos do Mais Médicos. Rio de Janeiro: Abrasco; 2018.

44. Sperling S. Política Nacional de Atenção Básica : consolidação do modelo de cuidado ou conciliação com o mercado de saúde? Saúde debate 2018; 42(n. spe 1):341-345.

45. Arouca S. Democracia é Saúde. In: Anais da $8^{a}$ Conferência Nacional de Saúde; 1986; Brasília.

Artigo apresentado em 30/05/2019

Aprovado em 07/08/2019

Versão final apresentada em 21/11/2019 